\title{
Neuroscience of foraging
}

\author{
Benjamin Y. Hayden ${ }^{1 *}$ and Mark E. Walton ${ }^{2}$ \\ 1 Department of Brain and Cognitive Sciences and Center for Visual Science, University of Rochester, Rochester, NY, USA \\ ${ }^{2}$ Department of Experimental Psychology, University of Oxford, Oxford, UK \\ *Correspondence: benhayden@gmail.com
}

Edited and reviewed by:

Hauke R. Heekeren, Freie Universität Berlin, Germany

Keywords: foraging, foraging theory, intertemporal choice, risk, ecological rationality, diet

The papers that accompany this Research Topic fall at the intersection of foraging theory and neuroscience. Why does such a topic merit a Research Topic in Frontiers in Decision Neuroscience? And what does foraging theory have to do with decision neuroscience?

Foraging theory was created in the 1960's, as behavioral ecologists began to absorb the intellectual advances in microeconomic theory of the 1940's and 50's, and apply its principles to their research. Early foraging theorists realized that animals can be thought of as economic decision-makers that thrive by learning to maximize benefits and minimize costs. A key insight was that adaptive fitness - the main driving influence in Darwinian evolution-behaves mathematically like any other economic good, and that we can analyze behavior by assuming animals seek to maximize it (McNamara and Houston, 1986; Stephens and Krebs, 1986).

While economics focuses on human problems, such selecting a brand of peanut butter or choosing a retirement plan, foraging theory focuses on animal problems. Early foraging theorists identified two major abstract problems: whether to accept or reject a prey item (the diet selection problem) and, when foraging in a prey-rich patch, when to leave it and move on to another one (the patch-leaving problem, Stephens and Krebs, 1986). Of course, these problems apply to humans as well, from the hunter-gatherer foraging for small animals to the internet surfer looking for interesting articles to pass the time.

In the diet selection problem, an animal (e.g., a fox) must decide, on encountering a prey (e.g., a pheasant) whether to pursue it or pass it up (Krebs et al., 1977). Foraging theorists realized that animals should integrate the costs and benefits of pursuit (presumably learned through experience) into a single decision variable and then compare that to specific threshold (also learned). The realization that the optimal strategy is a step-function and the method for computing this threshold were major early discoveries. Importantly, the threshold is a "background variable" that represents the marginal intake rate associated with the overall environment. In economic terms, it is the opportunity cost of pursuit. This example illustrates three key features of foraging problems: (1) they are fundamentally optimization problems that can be solved through costbenefit analyses, (2) they are modeled after problems encountered by animals, and (3) decisions are usually framed as a foreground (pursue) vs. background (ignore), rather than as two simultaneously presented alternatives as in standard economic tasks.
Several scholars have suggested that foreground-background decisions, even if they are mathematically identical to two-option choices common in economics, are mediated by distinct mental operations (Stephens, 2002). Indeed, it has been suggested that many animal decision-makers have difficulty making two-option choices, and use degenerate strategies evolved to solve foraging problems (Pavlic and Passino, 2010; Kacelnik et al., 2011). Furthermore, there is evidence that human decision-making is framed in terms or a default and an alternative, and that values of these options may be associated with specific brain regions (Kolling et al., 2012; Boorman et al., 2013). These findings highlight the utility of considering foraging-like problems when investigating the mechanisms of economic choice.

Indeed, results obtained in foraging conditions are often different from those obtained in economic tasks. For example, consider intertemporal choice tasks, in which animals choose between a large reward available after a long delay or a smaller reward available sooner. Animals typically reject the larger gains if the delay is more than a few seconds. This seemingly impulsive behavior has often been used to argue that most animal species discount future rewards heavily (Rachlin, 2000; Heilbronner et al., 2008; Kalenscher and Pennartz, 2008; Stevens and Stephens, 2008). Puzzlingly, however, in foraging tasks, animals discount only weakly or not at all (Stephens and Anderson, 2001; Hayden et al., 2011). Some scholars have suggested that the two-option structure of the standard intertemporal choice task is confusing for animals and that, because they misunderstand its structure, it produces highly biased estimates of discounting rates. In contrast, foraging tasks, with their naturally-inspired structure, do not (Bateson and Kacelnik, 1996; Kacelnik, 1997; Stephens, 2002; Pearson et al., 2010; Blanchard et al., 2013; Blanchard and Hayden, 2014).

Another example comes in the context of risky choice. Foraging theory emphasizes the serial and long-term strategic nature of risky choice, and thus suggests that decisions ought to be studied not solely in terms of non-linear utility-in other words, the prospect of an immediate gain or loss multiplied by its likelihood-but in terms of discontinuities between short and long-term strategies (Hayden and Platt, 2007; Heilbronner and Hayden, 2013). Whereas, economic theory often categorically classifies organisms into those that are risk seeking or are risk-averse, studies that look at repeated choices with uncertain outcomes find that both humans and other animals can adapt their choice strategies depending on the state of the environment, their current needs, and their long-term goals (Real and Caraco, 1986; Kolling et al., 2014). 
Foraging theory's emphasis on adaptive significance allows us to consider each species within its own ecological niche. For instance, most nutrition a rodent will encounter is at ground level; danger will likely come from above. Rodent superior colliculus (SC) maps precisely this distinction, with visual input from the upper quadrant of the visual field accessing the medial SC, which mediates defense responses, whereas the lower quadrant projects more strongly to lateral SC, stimulation of which results in approach behaviors (Comoli et al., 2012). The manual dexterity and trichromatic binocular vision of primates, and ultimately potentially the development of the prefrontal cortex, can also be related to their need to forage for ripe fruit and tender leaves in a visually complex, cluttered, and volatile environment (Passingham and Wise, 2012). As we neuroscientists try to collate fine-grained research from fruit flies and zebra fish to genetically modified rodents and primates, such ecological considerations will become increasingly pressing.

The papers included in this collection serve as an introduction to some of the major ideas that have influenced the nascent field of neural foraging. The most basic step in deriving a complete understanding of the neural basis of foraging is to understand the neural basis of the building blocks of foraging, food consumption, and executive control of decision-making. One goal is to make foraging theory more biological; whereas we assume that food consumption — often considered simply as "reward" in many neuroscience paradigms-is a "frictionless" process, it is in fact a very real and complex one. To understand it we must understand how it works (Caracheo et al., 2013; Horst and Laubach, 2013), and how it interacts with decision-making (Murray and Rudebeck, 2013). Simultaneously, foraging involves complex cognitive processes, and understanding how those work is critical for understanding the way that our minds constrains foraging decisions (Sallet et al., 2013). These include understanding of the neural representation of variables that are psychologically relevant to foraging decisions, like effort and risk (Miller et al., 2013), as well as social factors (Pearson et al., 2013). Traditional foraging theory tends to ignore factors that affect animal decisions like aging (Mata et al., 2013). Future work will also point toward linking economic ideas to foraging ideas, especially in the domain of time and risk (Bixter and Luhmann, 2013).

\section{ACKNOWLEDGMENTS}

This work was supported by a Sloan Foundation fellowship and a NSF Career Award (1253576) to BYH and a Wellcome Trust Research Career Development Fellowship (090051) to Mark E. Walton.

\section{REFERENCES}

Bateson, M., and Kacelnik, A. (1996). Rate currencies and the foraging starline: the fallacy of the averages revisited. Behav. Ecol. 7, 341-352. doi: 10.1093/beheco/ 7.3.341

Bixter, M. T., and Luhmann, C. C. (2013). Adaptive intertemporal preferences in foraging-style environments. Front. Neurosci. 7:93. doi: 10.3389/fnins. 2013.00093

Blanchard, T. C., and Hayden, B. Y. (2014). Neurons in dorsal anterior cingulate cortex signal postdecisional variables in a foraging task. J. Neurosci. 34, 646-655. doi: 10.1523/JNEUROSCI.3151-13.2014

Blanchard, T. C., Pearson, J. M., and Hayden, B. Y. (2013). Postreward delays and systematic biases in measures of animal temporal discounting. Proc. Natl. Acad. Sci. U.S.A. 110, 15491-15496. doi: 10.1073/pnas.1310446110
Boorman, E. D., Rushworth, M. F., and Behrens, T. E. (2013). Ventromedial prefrontal and anterior cingulate cortex adopt choice and default reference frames during sequential multi-alternative choice. J. Neurosci. 33, 2242-2253. doi: 10.1523/JNEUROSCI.3022-12.2013

Caracheo, B. F., Emberly, E., Hadizadeh, S., Hyman, J. M., and Seamans, J. K. (2013). Abrupt changes in the patterns and complexity of anterior cingulate cortex activity when food is introduced into an environment. Front. Neurosci. 7:74. doi: 10.3389/fnins.2013.00074

Comoli, E., Das Neves Favaro, P., Vautrelle, N., Leriche, M., Overton, P. G., and Redgrave, P. (2012). Segregated anatomical input to sub-regions of the rodent superior colliculus associated with approach and defense. Front. Neuroanat. 6:9. doi: 10.3389/fnana.2012.00009

Hayden, B. Y., Pearson, J. M., and Platt, M. L. (2011). Neuronal basis of sequential foraging decisions in a patchy environment. Nat. Neurosci. 14, 933-939. doi: 10.1038/nn.2856

Hayden, B. Y., and Platt, M. L. (2007). Temporal discounting predicts risk sensitivity in rhesus macaques. Curr. Biol. 17, 49-53. doi: 10.1016/j.cub.2006. 10.055

Heilbronner, S. R., and Hayden, B. Y. (2013). Contextual factors explain risk-seeking preferences in rhesus monkeys. Front. Neurosci. 7:7. doi: 10.3389/fnins.2013.00007

Heilbronner, S. R., Rosati, A. G., Stevens, J. R., Hare, B., and Hauser, M. D. (2008). A fruit in the hand or two in the bush? Divergent risk preferences in chimpanzees and bonobos. Biol. Lett. 4, 246-249. doi: 10.1098/rsbl.2008.0081

Horst, N. K., and Laubach, M. (2013). Reward-related activity in the medial prefrontal cortex is driven by consumption. Front. Neurosci. 7:56. doi: 10.3389/fnins.2013.00056

Kacelnik, A. (1997). Normative and descriptive models of decision making: time discounting and risk sensitivity. Ciba Found. Symp. 208, 51-70.

Kacelnik, A., Vasconcelos, M., Monteiro, T., and Aw, J. (2011). Darwin's "tug-ofwar" vs. starlings' "horse-racing": how adaptations for sequential encounters drive simultaneous choice. Behav. Ecol. Sociobiol. 65, 547-558. doi: 10.1007/ s00265-010-1101-2

Kalenscher, T., and Pennartz, C. M. A. (2008). Is a bird in the hand worth two in the future? The neuroeconomics of intertemporal decision-making. Prog. Neurobiol. 84, 284-315. doi: 10.1016/j.pneurobio.2007.11.004

Kolling, N., Behrens, T. E., Mars, R. B., and Rushworth, M. F. (2012). Neural mechanisms of foraging. Science 336, 95-98. doi: 10.1126/science. 1216930

Kolling, N., Wittman, M., and Rushworth, M. F. S. (2014). Multiple neural mechanisms of decision making and their competition under changing risk pressure. Neuron 81, 1190-1202. doi: 10.1016/j.neuron.2014.01.033

Krebs, J. R., Erichsen, J. T., Webber, M. I., and Charnov, E. L. (1977). Optimal prey selection in the great tit (Parus major). Anim. Behav. 25, 30-38. doi: 10.1016/ 0003-3472(77)90064-1

Mata, R., Wilke, A., and Czienskowski, U. (2013). Foraging across the life span: is there a reduction in exploration with aging? Front. Neurosci. 7:53. doi: 10.3389 /fnins. 2013.00053

McNamara, J. M., and Houston, A. I. (1986). The common currency for behavioral decisions. Am. Nat. 127, 358-378. doi: 10.1086/284489

Miller, M. A., Thomé, A., and Cowen, S. L. (2013). Intersection of effort and risk: ethological and neurobiological perspectives. Front. Neurosci. 7:208. doi: 10.3389/fnins.2013.00208

Murray, E. A., and Rudebeck, P. H. (2013). The drive to strive: goal generation based on current needs. Front. Neurosci. 7:112. doi: 10.3389/fnins.2013. 00112

Passingham, R. E., and Wise, S. P. (2012). The Neurobiology of the Prefrontal Cortex: Anatomy, Evolution, and the Origin of Insight. Oxford: Oxford University Press.

Pavlic, T. P., and Passino, K. M. (2010). When rate maximization is impulsive. Behav. Ecol. Sociobiol. 64, 1255-1265. doi: 10.1007/s00265-010-0940-1

Pearson, J. M., Hayden, B. Y., and Platt, M. L. (2010). Explicit information reduces discounting behavior in monkeys. Front. Psychol. 1:237. doi: 10.3389/fpsyg. 2010.00237

Pearson, J. M., Watson, K. K., Klein, J. T., Ebitz, R. B., and Platt, M. L. (2013). Individual differences in social information gathering revealed through Bayesian hierarchical models. Front. Neurosci. 7:165. doi: 10.3389/fnins.2013. 00165

Rachlin, H. (2000). The Science of Self-Control. Cambridge, MA: Harvard University Press. 
Real, L., and Caraco, T. (1986). Risk and foraging in stochastic environments. Annu. Rev. Ecol. Syst. 17, 371-390. doi: 10.1146/annurev.es.17.110186.002103

Sallet, J., Camille, N., and Procyk, E. (2013). Modulation of feedback-related negativity during trial-and-error exploration and encoding of behavioral shifts. Front. Neurosci. 7:209. doi: 10.3389/fnins.2013.00209

Stephens, D. W. (2002). Discrimination, discounting and impulsivity: a role for an informational constraint. Philos. Trans. R. Soc. Lond. B Biol. Sci. 357, 1527-1537. doi: $10.1098 /$ rstb.2002.1062

Stephens, D. W., and Anderson, D. (2001). The adaptive value of preference for immediacy: when shortsighted rules have farsighted consequences. Behav. Ecol. 12, 330-339. doi: 10.1093/beheco/12.3.330

Stephens, D. W., and Krebs, J. R. (1986). Foraging Theory. Princeton, NJ: Princeton University Press.

Stevens, J. R., and Stephens, D. W. (2008). Patience. Curr. Biol. 18, 11-12. doi: 10. 1016/j.cub.2007.11.021
Conflict of Interest Statement: The authors declare that the research was conducted in the absence of any commercial or financial relationships that could be construed as a potential conflict of interest.

Received: 21 February 2014; accepted: 31 March 2014; published online: 21 April 2014. Citation: Hayden BY and Walton ME (2014) Neuroscience of foraging. Front. Neurosci. 8:81. doi: 10.3389/fnins.2014.00081

This article was submitted to Decision Neuroscience, a section of the journal Frontiers in Neuroscience.

Copyright (C) 2014 Hayden and Walton. This is an open-access article distributed under the terms of the Creative Commons Attribution License (CC BY). The use, distribution or reproduction in other forums is permitted, provided the original author(s) or licensor are credited and that the original publication in this journal is cited, in accordance with accepted academic practice. No use, distribution or reproduction is permitted which does not comply with these terms. 